\title{
Spatial probability learning and brain stimulation in rats
}

\author{
ROGER N. JOHNSON, ${ }^{1}$ Tufts University, \\ Medford, Mass. 02155
}

Five rats were run for 3,000 trials with ICS as a reinforcer on a 70:30 spatial probability problem employing a correction procedure. All Ss responded to the more frequently rewarded side most of the time. However, none completely maximized.

A previous experiment (Johnson \& Levy, 1969) examined probability learning in rats run for an extensive number of trials (up to 8,000 ), in which reinforcement consisted of brain stimulation. The use of spatial discriminations and a noncorrection procedure was expected to favor maximizing behavior (Bitterman, Wodinsky, \& Candland, 1958; Parducci \& Polt, 1958; Poland \& Warren, 1967). However, only one rat out of eight clearly maximized. The present experiment was carried out in a similar fashion except that a correction procedure was used in an effort to obtain more systematic behavior. SUBJECTS

Five male Long-Evans rats, about 100 days old, were stereotaxically implanted with bipolar electrodes, .014 in. in diam, aimed at the lateral hypothalamus (flat brain coordinates: $1.5 \mathrm{~mm}$ lateral, $3.5 \mathrm{~mm}$ behind bregma, $8.5 \mathrm{~mm}$ below skull surface).

APPARATUS AND PROCEDURE

The apparatus is the same one previously described (Johnson, 1968; Johnson \&

Fig. 1. Mean per cent of initial responses to the more frequently rewarded side in a 70:30 spatial problem. others (Mackintosh, 1967; Poland \& Warren, 1968) noting the failure to obtain clear maximizing, and tend to support Mackintosh's interpretation that probability-learning scores represent quantitative rather than qualitative differences in learning.

More surprising than the final level of performance under the conditions of the present experiment (massed trials, ICS reinforcement) is the speed at which it is reached. After 500 trials, $\mathbf{S s}$ are still clearly matching, and it is only after about 1,000 trials that they reach the $90 \%$ level. This contrasts with the data of Bitterman, Wodinsky, \& Candland (1958), which show that, with a 70:30 spatial problem and guidance procedure, rats reach the $90 \%$ level after about 120 trials. It would appear that training conditions can be as important as species differences in determining overall performance.

$$
\text { REFERENCES }
$$

BITTERMAN, M. E., WODINSKY, J., \& CANDLAND, D. K. Some comparative psychology. American Journal of Psychology, 1958, 71, 94-110.

JOHNSON, R. N, Effects of intracranial reinforcement intensity and distributional variables on brightness reversal learning by rats. Journal of Comparative \& Physiological Psychology, 1968, 66, 422-426.

JOHNSON, R. N., \& LEVY, R. S. Probability learning in rats reinforced with brain stimulation. Psychonomic Science, 1969, 14, 27-28.

MACKINTOSH, N. J. Comparative psychology of reversal and probability learning. Paper presented at meetings of the Experimental A nalysis of Behavior Group, Brighton, England, April 6, 1967.

PARDUCCI, A., \& POLT, J. Correction vs noncorrection with changing reinforcement schedules. Journal of Comparative \& Physiological Psychology, 1958, 51, 492-495.

POLAND, S. F., \& WARREN, J. M. Spatial probability learning by cats. Psychonomic Science, $1967,8,487-488$.

POLAND, S. F., \& WARREN, J. M. Cats' performance on visual probability learning problems after prolonged training. Journal of Comparative \& Physiological Psychology, $1968,65,545-546$. NOTE

l. Supported by faculty research grant, Tufts University.

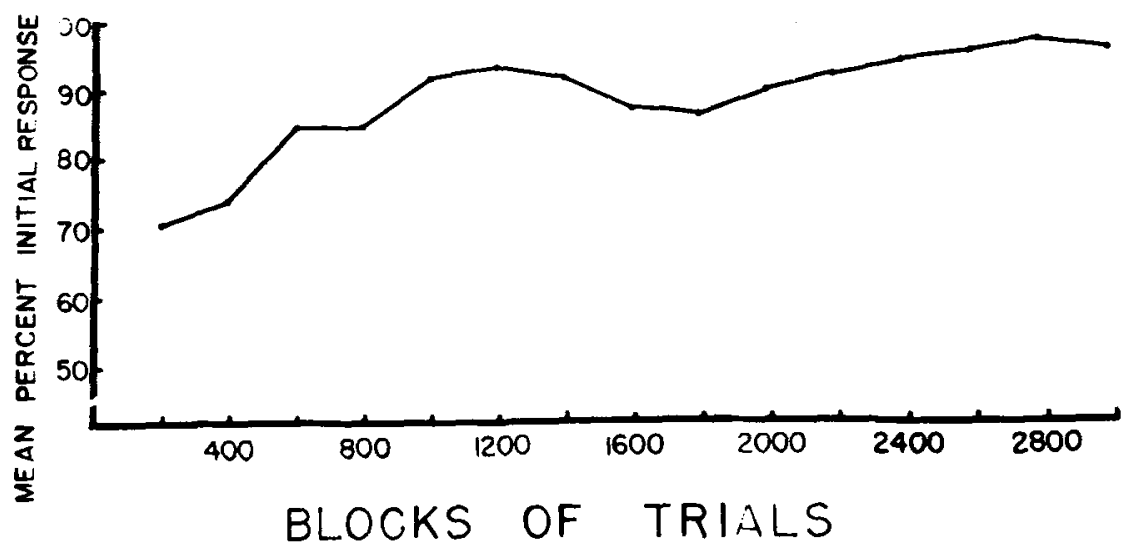

